\title{
Supramolecular Nanocarrier of siRNA from PEG-Based Block Catiomer Carrying Diamine Side-Chain with Distinctive pKa Directed to Enhance Intracellular Gene Silencing
}

\author{
Keiji Itaka†t, Naoki Kanayama†, Nobuhiro Nishiyama†, Woo-Dong Jang†, Yuichi \\ Yamasaki†, Kozo Nakamura $\ddagger$, Hiroshi Kawaguchił, and Kazunori Kataoka*† \\ $\dagger$ Department of Materials Science and Engineering, Graduate School of Engineering, and \\ $\ddagger$ Department of Orthopaedic Surgery, Faculty of Medicine, University of Tokyo, 7-3-1 Hongo, \\ Bunkyo-ku, Tokyo 113-8656, Japan
}

Materials and methods

\section{Materials}

siRNA samples (GL3 targeting, Lamin A/C targeting, and non-targeting) were purchased from QIAGEN (the pre-designed Library siRNA). Plasmid DNAs (pDNA) encoding luciferase (pGL3-Control, Promega; 5256 bps and pRL-TK, Promega; 4045 bpa) were amplified in competent DH5 $\alpha$ Escherichia-coli and purified using EndoFree ${ }^{\mathrm{TM}}$ Plasmid Maxi or Mega Kits (QIAGEN). The siRNA and DNA concentration was determined by reading the absorbance at $260 \mathrm{~nm}$. LipofectAMINE ${ }^{\mathrm{TM}}$ and RNAiFect ${ }^{\mathrm{TM}}$ were purchased from Invitrogen and QIAGEN, respectively. Dulbecco's modified eagle medium (DMEM) and fetal bovine serum (FBS) were purchased from Sigma. OPTI-MEM I Reduced Serum Medium was purchased from Invitrogen.

Synthesis and Characterization of PEG-DPT block copolymers PEG-poly( $\beta$-benzyl-L-aspartate) (PEG-PBLA) diblock copolymer was synthesized by the ring-opening polymerization of $\beta$-benzyl-L-aspartate $N$-carboxy-anhydride (BLA-NCA) from the terminal primary amino group of $\alpha$-methoxy- $\omega$-amino poly(ethylene glycol) (Mw: 12,000; Nippon Oil and Fats Co., Ltd.). ${ }^{1)} \quad$ The block copolymer thus prepared was confirmed to be unimodal with a narrow molecular weight distribution $\left(\mathrm{M}_{\mathrm{w}} / \mathrm{M}_{\mathrm{n}}\right.$ : 1.23) by GPC, and the number of repeating units of BLA was calculated to be 68 from the ${ }^{1} \mathrm{H}-\mathrm{NMR}$ (data not shown). The acetylation of amino group of $N$-terminal of PEG-PBLA was then performed using acetic anhydride in dichloromethane solution to obtain PEG-PBLA-Ac. The obtained polymer was dissolved in distilled $N, N$-dimethylformamide (DMF) (Wako Pure Chemical Industries, Ltd. (Osaka, Japan)), and reacted with dipropylenetriamine 
(DPT) (Tokyo Kasei Kogyo Co., Ltd. (Tokyo, Japan)) for 24 hours at $40^{\circ} \mathrm{C}$ under a dry argon atmosphere to undergo aminolysis of benzyl side chain. After 24 hours, the solution was slowly dropped into 10 \% acetic acid solution and dialyzed (Spectrapor@, Membrane, $\mathrm{MWCO}=3500$ ) against $0.01 \mathrm{~N} \mathrm{HCl}$, and subsequently against distilled water. The final solution was lyophilized to obtain PEG-DPT as the hydrochloride salt form. Complete substitution of benzyl ester of the polymer with DPT through the aminolysis reaction as well as the chemical structure of the obtained PEG-DPT block copolymer were confirmed by ${ }^{1} \mathrm{H}-\mathrm{NMR}$ as shown in Fig. S1

1) Harada, A; Kataoka, K. Macromolecules 1995, 28, 5294-5299.

Synthesis of model compounds

Tert-butoxycarbonyl- $\beta$-benzyl-(L)-aspartate (Boc-Asp(Bz)):

A tetrahydrofuran (THF) solution $(50 \mathrm{~mL})$ of a mixture of $\beta$-benzyl-(L)-aspartate (45 $\mathrm{mmol})$, di-tert-butyl dicarbonate $(50 \mathrm{mmol})$, and triethylamine $(50 \mathrm{mmol})$, containing 10 $\mathrm{ml}$ of water, was stirred under $\mathrm{Ar}$ at $25{ }^{\circ} \mathrm{C}$ for 30 minutes. The reaction mixture was poured into water saturated with $\mathrm{NaHCO}_{3}(30 \mathrm{ml})$, and washed with ethyl acetate $(3 \times 50$ $\mathrm{ml}$ ). The aqueous layer was neutralized with aqueous hydrochloric acid and then extracted with ethyl acetate. The ethyl acetate solution thus obtained was evaporated to obtain Boc-Asp(Bz) as white crystalline solid in 50\% yield. ${ }^{1} \mathrm{H}$ NMR $\left(\mathrm{CDCl}_{3}\right): \delta 1.45(\mathrm{~s}$, 9H; tert-Bu), 2.85-3.10 (m, 2H; - $\mathrm{CH}_{2}$ - in Asp), 4.63 (m, 1H; -CH-), 5.16 (s, 2H; - $\mathrm{CH}_{2}-\mathrm{Ar}$ ), $5.55(\mathrm{~d}, 1 \mathrm{H} ; \mathrm{NH}), 7.36\left(\mathrm{~m}, 5 \mathrm{H} ;-\mathrm{C}_{6} \mathrm{H}_{5}\right)$.

Tert-butoxycarbonyl- $\beta$-benzyloxycarbonyl- $\alpha-N$-propyl-(L)-aspartamide (Boc-Asp(Bz)-Pr): A dichloromethane solution $(50 \mathrm{ml})$ of a mixture of Boc-Asp(Bz) $(22 \mathrm{mmol})$, propyl amine (22 mmol), ethyl-3-(3-dimethylaminopropyl)carbodiimide hydrochloride (25 mmol), and 1-hydroxybenzotriazole $(25 \mathrm{mmol})$ was stirred under Ar at $0{ }^{\circ} \mathrm{C}$ for 12 hours. The reaction mixture was poured into ethyl acetate $(200 \mathrm{ml})$ and washed with $\mathrm{NaHCO}_{3}$ saturated water $(3 \times 50 \mathrm{ml})$ and aqueous $1 \mathrm{~N} \mathrm{HCl}(3 \times 50 \mathrm{ml})$, successively. The ethyl acetate solution thus obtained was evaporated to dryness and then freeze-dried from benzene to give Boc-Asp(Bz)-pr as white solid in 95\% yield. ${ }^{1} \mathrm{H}$ NMR $\left(\mathrm{CDCl}_{3}\right): \delta 0.88$ (t, $\left.3 \mathrm{H} ;-\mathrm{CH}_{2} \mathrm{CH}_{2} \mathrm{CH}_{3}\right), 1.45$ (s, 9H; tert-Bu), 1.52 (m, 2H; - $\left.\mathrm{CH}_{2} \mathrm{CH}_{2} \mathrm{CH}_{3}\right), 2.67-3.09$ (m, $2 \mathrm{H}$; - $\mathrm{CH}_{2}$ - in Asp), 3.21 (m, 2H,- $\mathrm{CH}_{2} \mathrm{CH}_{2} \mathrm{CH}_{3}$ ), 4.48 (m, 1H; -CH-), 5.13 (d, 2H; - $\mathrm{CH}_{2}-\mathrm{Ar}$ ), 5.67 (br, 1H; -OCONHC-), 6.46 (br, 1H; -CCONHC-), 7.35 (m, 5H; - $\mathrm{C}_{6} \mathrm{H}_{5}$ ). 
Tert-butoxycarbonyl- $\beta$ - $N$-3-(3-aminopropyl)aminopropylamido- $\alpha-N$-propyl-(L)-aspartami de (Boc-Asp(DPT)-Pr):

A THF solution $(10 \mathrm{ml})$ of a mixture of Boc-Asp(Bz)-pr $(0.7 \mathrm{mmol})$ and di-(3-aminopropyl)amine (70 mmol) was refluxed under Ar for 12 hours. The reaction mixture was poured into water $(50 \mathrm{ml})$ and washed with dichloromethane. To the aqueous layer thus obtained was added $50 \mathrm{ml}$ of aqueous $2 \mathrm{~N} \mathrm{NaOH}$ and successively extracted with ethyl acetate $(50 \mathrm{ml} \times 5)$. The extract was evaporated to dryness to give Boc-Asp(DPT)-Pr as transparent oil in 3\% yield. ${ }^{1} \mathrm{H}$ NMR $\left(\mathrm{CDCl}_{3}\right): \delta 0.90(\mathrm{t}, 3 \mathrm{H}$; $\left.-\mathrm{CH}_{2} \mathrm{CH}_{2} \mathrm{CH}_{3}\right), 1.45$ (s, 9H; tert-Bu), 1.49 (m, 2H; $\left.-\mathrm{CH}_{2} \mathrm{CH}_{2} \mathrm{CH}_{3}\right), 1.67$ (m, 4H; $-\mathrm{NCH}_{3} \mathrm{CH}_{3} \mathrm{CH}_{3} \mathrm{~N}-$ ), 1.81 (br, $3 \mathrm{H}$; amines), 2.46-2.85 (m, $8 \mathrm{H}$; $-\mathrm{CH}_{2}$ - in Asp, $-\mathrm{CH}_{2} \mathrm{NHCH}_{2}-$, and $-\mathrm{CH}_{2} \mathrm{NH}_{2}$ ), 3.17-3.98 (m, 4H,-CONHCH $2_{2}^{-}$), 4.40 (m, 1H; -CH-), 6.21-7.59 (m (br), $3 \mathrm{H}$; - $\mathrm{CONH}-$ ).

\section{Preparation of siRNA complexes}

The PEG-based block catiomer and siRNA were separately dissolved in 10mM Tris-HCl buffer ( $\mathrm{pH}$ 7.4). Both solutions were mixed at various $\mathrm{N} / \mathrm{P}$ (= [total amines in cationic segment]/[siRNA phosphates]) and left for an hour. The final concentration of siRNA was adjusted to $2.7 \mu \mathrm{M}$. The RNAiFect/siRNA complex was prepared by mixing the siRNA solution and RNAiFect TM reagent following the protocol provided by the manufacturer.

siRNA transfection (GL3 luciferase knockdown)

The HuH-7 cells were seeded in 24 -well culture plates $\left(3 \times 10^{4}\right.$ cells/well). After a 24-hour incubation in DMEM containing 10\% FBS, the cells were rinsed and then $250 \mu \mathrm{l}$ of OPTI-MEM I medium was added to each well. For the pre-transfection of both GL3 and RL luciferases, $0.7 \mu \mathrm{g}$ of pGL3 and $0.07 \mu \mathrm{g}$ of pRL were applied to each well after complexing with LipofectAMINETM, followed by 4-hour incubation. Then, after removing the medium and rinsing twice, $250 \mu 1$ of DMEM containing 10\% FBS was added to each well and $12 \mu 1$ of the siRNA complex solution was applied. The siRNA concentration in the culture medium was $120 \mathrm{nM}$. After a further 48 hours of incubation, the GL3 and RL luciferase gene expressions were measured by the Dual Luciferase Assay Kit (promega) and a luminometer (Lumat LB 9507, Berthold). The GL3 gene knockdown was evaluated as the expression ratio of GL3/RL. For the preincubation study with serum, the siRNA complex solutions were incubated in $50 \%$ serum at $37^{\circ} \mathrm{C}$ 
prior to transfection.

Endogenous gene (Lamin A/C) knockdown

The HuH-7 and $293 \mathrm{~T}$ cells were seeded in 24-well culture plates. After a 24-hour incubation in DMEM containing 10\% FBS, the cells were rinsed and replaced by $1 \mathrm{ml}$ of DMEM containing $10 \%$ FBS. Then, $48 \mu \mathrm{l}$ of the siRNA (Lamin A/C targeting and non-targeting) complex solution was applied.

After 48-hour incubation, the total mRNA was collected by using RNeasy Mini Preparation Kit (QIAGEN) according to the manufacturer's protocol. The gene expression was analyzed using quantitative RT-PCR. $20 \mathrm{ng}$ of total RNA was analyzed in a final volume of $20 \mu \mathrm{l}$ by using the Quantitect SYBR Green RT-PCR Kit (QIAGEN) according to the manufacturer's protocol. Reverse transcription was performed for 30 minutes at $50{ }^{\circ} \mathrm{C}$ followed by PCR: 40 thermal cycles of $15 \mathrm{sec}$ at $94{ }^{\circ} \mathrm{C}$ and $30 \mathrm{sec}$ at $55{ }^{\circ} \mathrm{C}$ and $30 \mathrm{sec}$ at $72{ }^{\circ} \mathrm{C}$ using an ABI Prism 7000 Sequence Detector (Applied Biosystems). All mRNA expression was normalized to levels of GAPDH mRNA, also determined by quantitative RT-PCR, from the same total RNA samples. The following primers were used: Lamin A/C; forward primer (CAAGAAGGAGGGTGACCTGA) and reverse primer (GCATCTCATCCTGAAGTTGCTT), GAPDH; forward primer (GAAGGTGAAGGTCGGAGTC), reverse primer (GAAGATGGTGATGGGATTTC).

\section{Cytotoxicity Assay}

The cytotoxicities of siRNA/ PEG-based block catiomer complexes were evaluated by an MTT assay (Cell Counting Kit: Dojindo). HuH-7 cells were plated into 96-well culture plates $\left(7 \times 10^{3}\right.$ cells/well). The medium was removed 24 hours later and 100 $\mu 1$ DMEM (with 10\% FBS) and $5 \mu 1$ of the siRNA complex solution was added to each well. After 48-hour incubation, the viability of the cells in each well was measured by reading the absorbance at $415 \mathrm{~nm}$, according to the protocol provided by the manufacturer. 
Figure S1

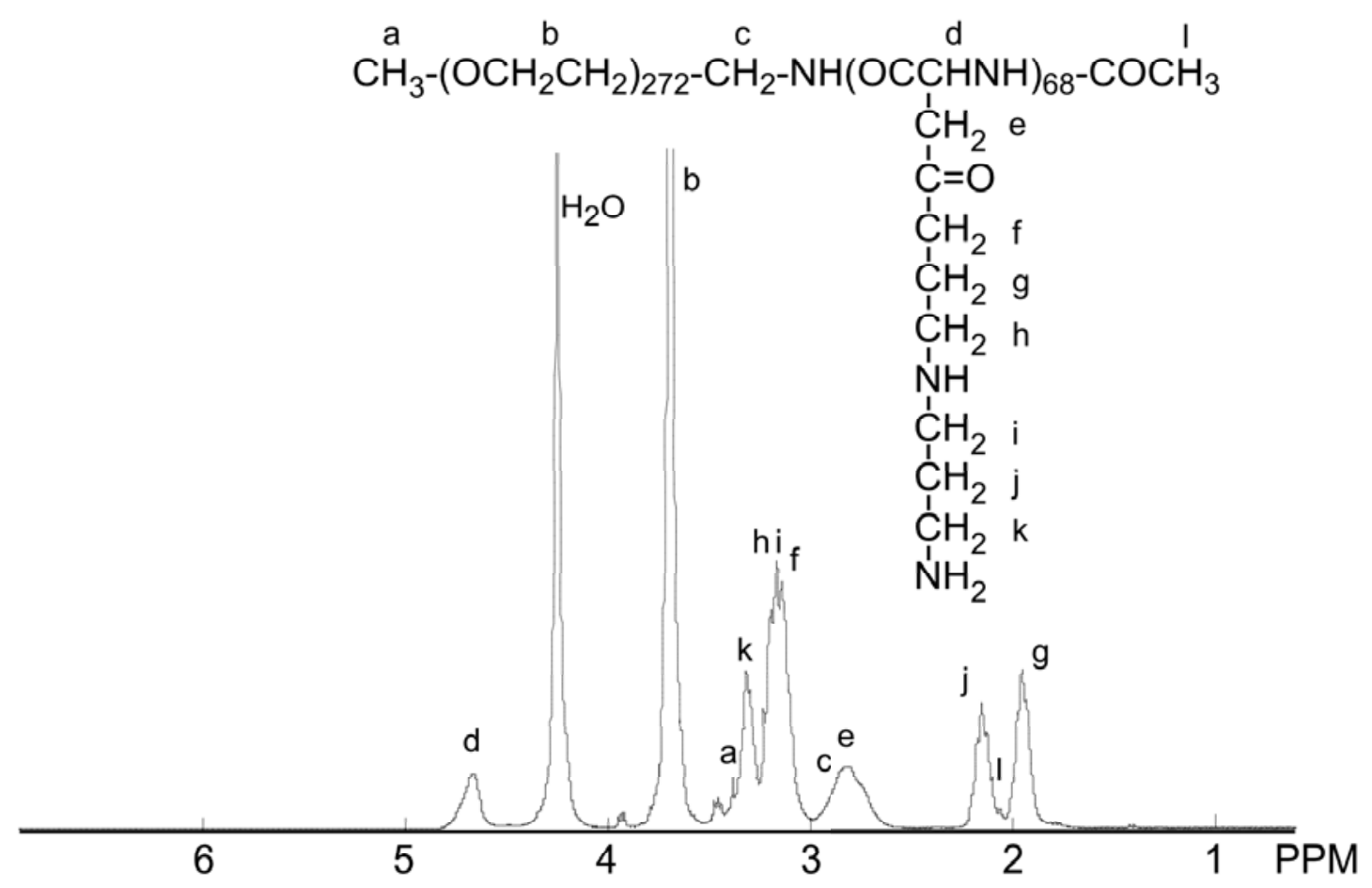

1H-NMR spectrum of PEG-DPT block copolymer; solvent: D2O; temperature: $80^{\circ} \mathrm{C}$; accumulation: 256 times. 
Figure S2

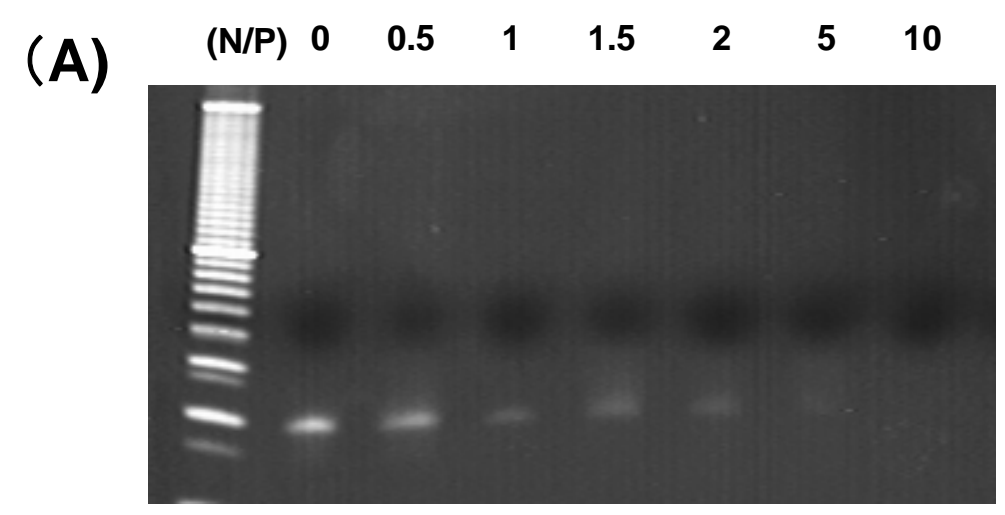

(B)

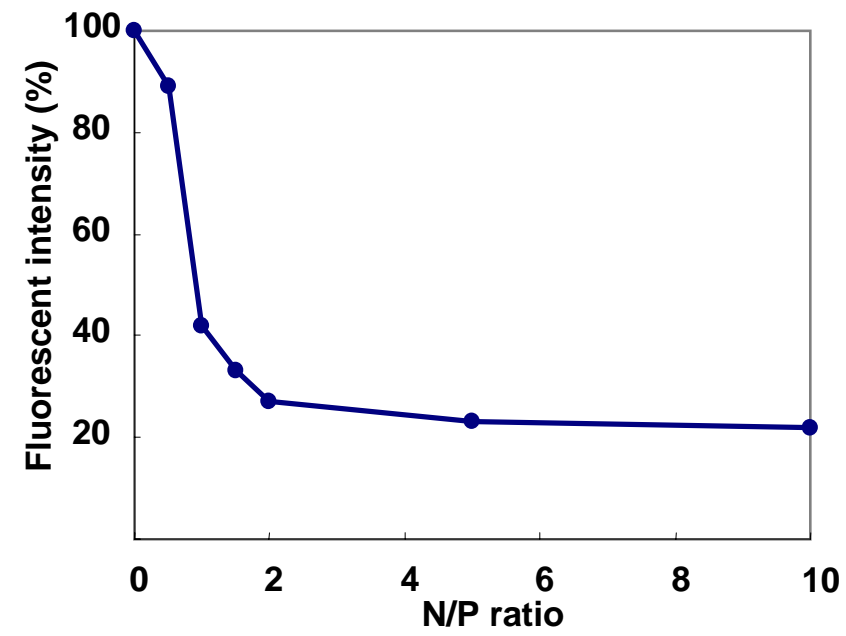

(A) Polyacrylamide gel electrophoresis (PAGE) and (B) ethidium bromide (EtBr) exclusion assay of PEG-DPT/siRNA complexes. 
Figure S3

PEG-PLL

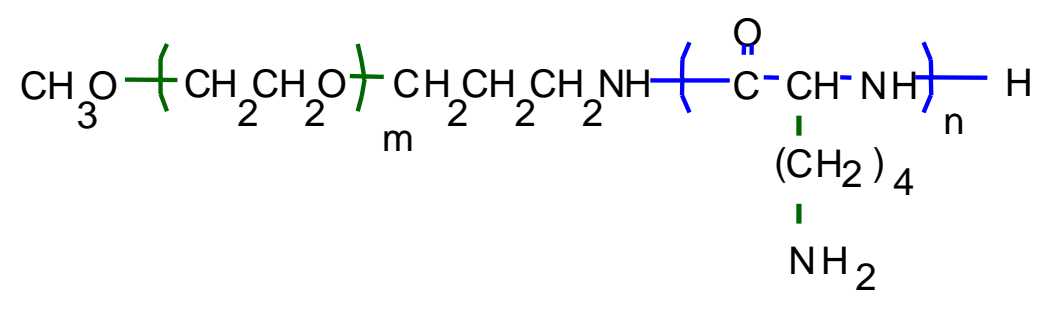

PEG-DMAPA

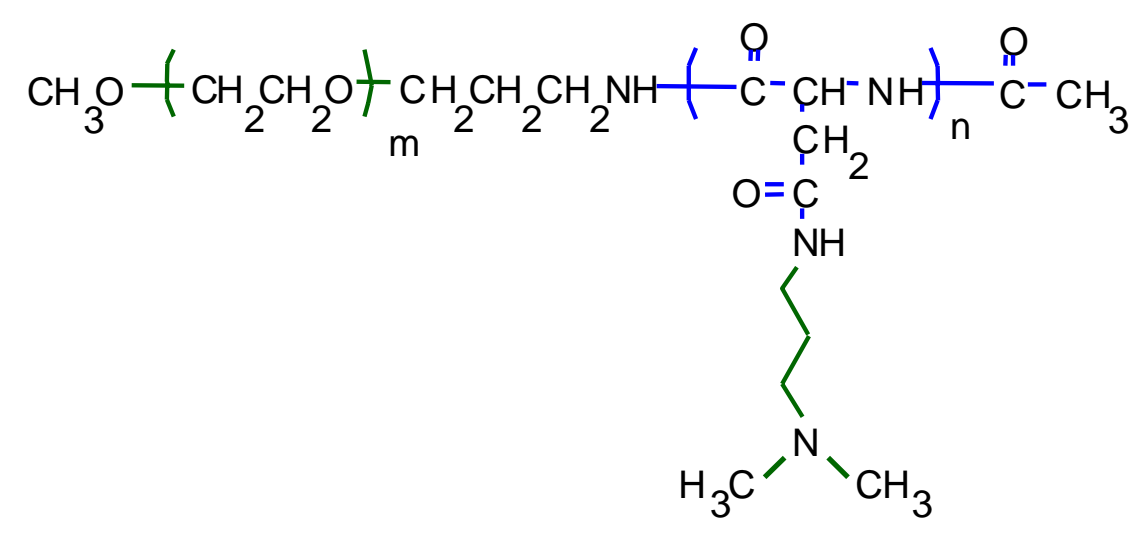

Chemical structures of (A) PEG-PLL and (B) PEG-DMAPA. 
Figure S4

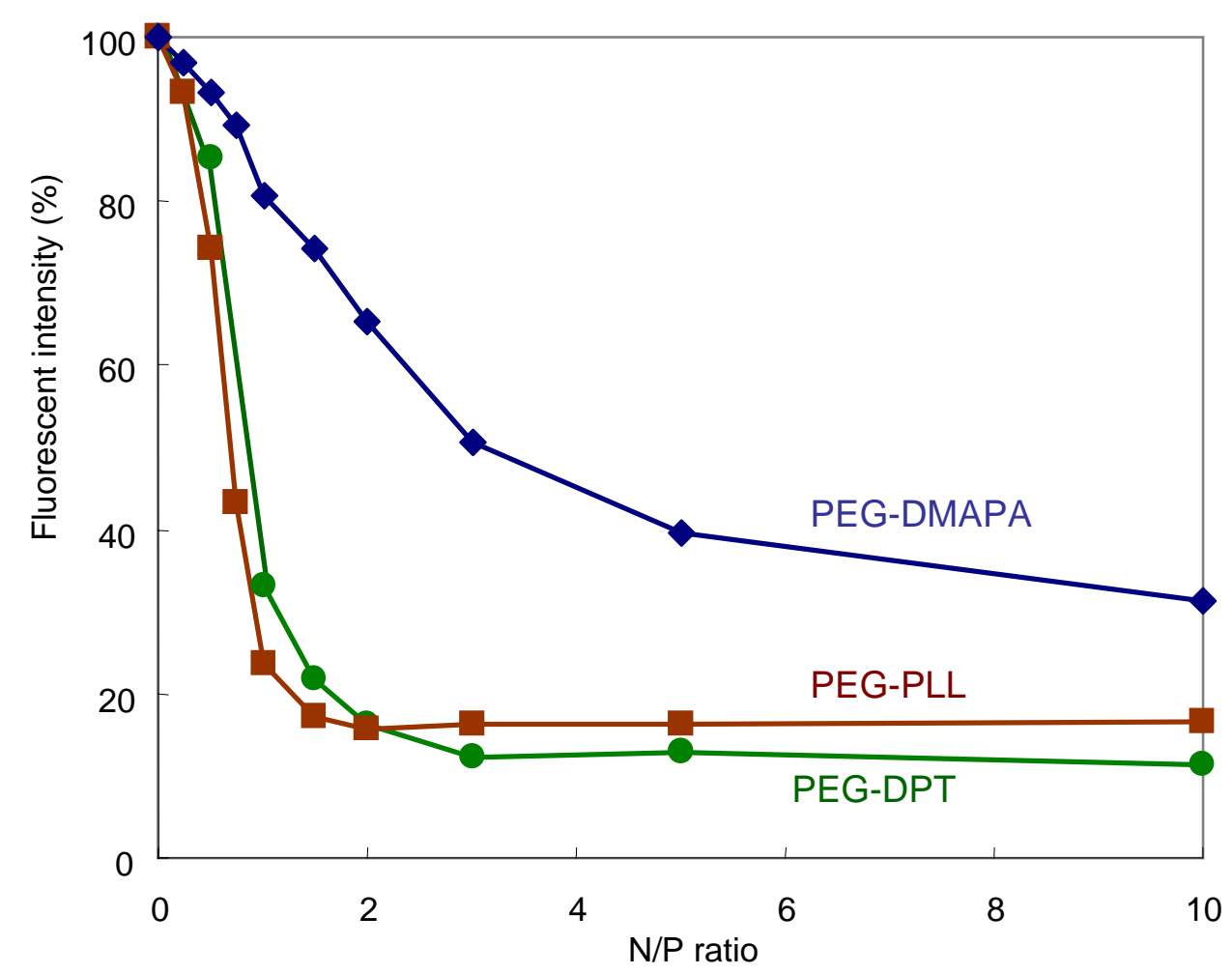

Ethidium bromide (EtBr) exclusion assay of PEG-DPT, PEG-PLL, and PEG-DMAPA/ds-oligo DNA complexes. 
Figure S5

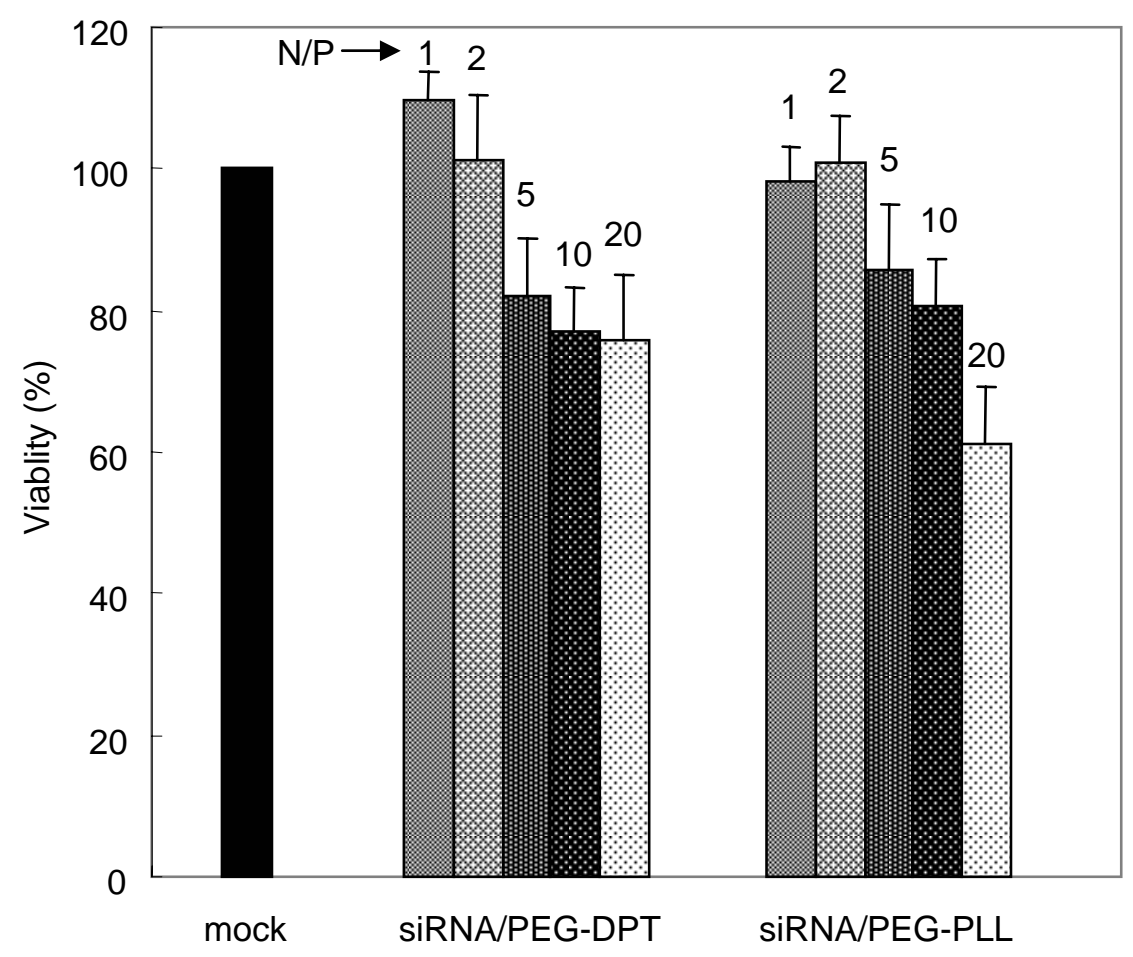

Cell viability after co-incubation with siRNA/PEG-DPT and siRNA/PEG-PLL complexes for 48 hours ( $n=12$; \pm S.D.) . 